\title{
Selective Destruction of Stable Microtubules and Axons by Inhibitors of Protein Serine/Threonine Phosphatases in Cultured Human Neurons (NT2N Cells)
}

\author{
Sandra E. Merrick, John Q. Trojanowski, and Virginia M.-Y. Lee \\ Department of Pathology and Laboratory Medicine, The Center for Neurodegenerative Disease Research, \\ The University of Pennsylvania School of Medicine, Philadelphia, Pennsylvania 19104-4283
}

Paired helical filaments (PHFs) in the neurofibrillary tangles (NFTs) in Alzheimer's disease (AD) brains are composed of highly phosphorylated isoforms of tau (PHFtau) that fail to bind microtubules (MTs), and the levels of MT-binding competent tau are decreased in AD brains with abundant PHFtau. Because this loss of MT binding could compromise the viability of tanglebearing $A D$ neurons by destabilizing MTs, we asked whether these events could be initiated by inhibiting protein phosphatase 1 (PP1) and PP2A in cultured human neurons (NT2N cells) using okadaic acid (OK) and calyculin-A (CL-A). The treatment of NT2N cells with OK and CL-A increased tau phosphorylation, decreased the binding of tau to MTs, and selectively depolymerized the more stable detyrosinated MTs but not the more labile tyrosinated MTs. Significantly, this led to the rapid degeneration of axons, which are enriched in the more stable detyrosinated MTs, and PP2A was implicated in the initiation of this cascade of events because PP2A but not PP1 was closely associated with MTs in the NT2N cells. These studies imply that inactivation of PP2A in vulnerable neurons of the $A D$ brain may play a mechanistic role in the conversion of normal tau into PHFtau, in the depolymerization of stable MTs, and in the degeneration of axons emanating from tanglebearing neurons.

Key words: Alzheimer's disease; paired helical filaments; protein phosphatase 1; protein phosphatase 2A; tau; cytoskeleton
Paired helical filaments (PHFs), the dominant structures in the neurofibrillary tangles (NFTs) in the Alzheimer's disease (AD) brain, are composed of hyperphosphorylated isoforms of tau known as PHFtau (for recent reviews, see Lee and Trojanowski, 1995; Trojanowski et al., 1996; Goedert et al., 1997). Tau is a microtubule (MT)-associated protein that binds to and stabilizes MTs in addition to promoting MT assembly (Weingarten et al., 1975; Drubin et al., 1986; Goode and Feinstein, 1994). The binding of tau to MTs is regulated by phosphorylation such that PHFtau binds poorly to MTs (Lindwall and Cole, 1984; Bramblett et al., 1993; Drewes et al., 1995) and binds to MTs only after enzymatic dephosphorylation (Bramblett et al., 1993). Because the level of MT-binding competent tau is reduced in regions of the AD brain with abundant NFTs and PHFtau (Bramblett et al., 1992), this decrease may lead to the depolymerization of MTs and may compromise neuronal viability in $\mathrm{AD}$ by disrupting axonal transport (Lee and Trojanowski, 1995; Trojanowski et al., 1996; Goedert et al., 1997).

Initially, the sites and the extent of the phosphorylation of PHFtau distinguished PHFtau from autopsy-derived normal adult brain tau (Lee et al., 1991; Hasegawa et al., 1992; Goedert et al., 1993, 1994; Morishima-Kawashima et al., 1995). Although

Received April 11, 1997; revised May 8, 1997; accepted May 13, 1997.

This work was supported by grants from the National Institute on Aging of the National Institutes of Health. We gratefully acknowledge Dr. M. Black for thoughtful discussions, and we also thank Ms. C. Page, Mr. T.-H. Chiu, and Mr. Lew Johns for their assistance with tissue culture, photography, and immunoelectron microscopy, respectively. Drs. L. Binder, G. Gundersen, C. Bulinski, P. Davies, and B. Hemmings are thanked for contributing antibodies to this study.

Correspondence should be addressed to Dr. Virginia M.-Y. Lee, Department of Pathology and Laboratory Medicine, The Center for Neurodegenerative Disease Research, The University of Pennsylvania School of Medicine, Maloney 3, HUP, Philadelphia, PA 19104-4283.

Copyright (C) 1997 Society for Neuroscience $\quad 0270-6474 / 97 / 175726-12 \$ 05.00 / 0$
PHFtau could be generated by overactive kinases, studies of biopsy-derived normal brain tau implicated inactive phosphatases in the formation of PHFtau (Matsuo et al., 1994). Furthermore, most of the putative "abnormal" phosphorylation sites in PHFtau have been shown now to be phosphorylated in rapidly processed normal rat and human brain tau (Matsuo et al., 1994; MawalDewan et al., 1994). Thus, PHFtau seems to result from the excessive phosphorylation of normal phosphate acceptor residues in tau by overactive kinases and/or by hypoactive phosphatases. However, it is unknown whether this imbalance of kinase and phosphatase activities has a direct effect on MT stability in neurons of the AD brain.

Previous studies have shown that MT functions require a dynamic equilibrium between polymerized and depolymerized MTs (Saxton et al., 1984; Schulze et al., 1987; Webster et al., 1987b). A subset of MTs exhibit long turnover rates (Webster et al., 1987a) and an increased resistance to MT-depolymerizing drugs (Khawaja et al., 1988). This more stable pool of MTs contains detyrosinated $\alpha$-tubulin (Glu-tubulin) that is generated posttranslationally by the removal of the Tyr residue from the $\mathrm{C}$ terminus of the more dynamic form of $\alpha$-tubulin (Tyr-tubulin) (Gundersen and Bulinski, 1988; Bulinski and Gundersen, 1991). Significantly, cultured postmitotic sympathetic neurons express much more Glu-MTs than rapidly dividing Chinese hamster ovary cells express (50 vs 1-2\%; Gundersen et al., 1984; Bass and Black, 1990), and axons contain a higher percentage of stable MTs than dendrites (58 vs 25\%; Baas et al., 1991). However, the mechanisms that regulate the dynamic equilibrium between polymerized and depolymerized MTs in neurons are incompletely understood, and it is unclear how an imbalance of kinases and phosphatases leads to the formation of PHFtau, perturbs MTs, and contributes to the degeneration of neurons in $\mathrm{AD}$. 
Using cultured NT2N cells as an in vitro model of human neurons (Pleasure et al., 1992), we showed that the inhibition of protein phosphatases such as protein phosphatase 2A (PP2A) could play a mechanistic role in the conversion of normal tau into PHFtau, in the disruption of MTs, and in the degeneration of tangle-bearing neurons in AD.

\section{MATERIALS AND METHODS}

Cell culture. The NTera-2 (NT2) cells isolated from a human teratocarcinoma-derived embryonal carcinoma cell line (Andrews et al., 1984; Lee and Andrews, 1986) were grown and maintained as described (Pleasure et al., 1992). NT2 cells were treated with retinoic acid for 5 weeks to induce differentiation into postmitotic neuron-like cells (NT2N cells) and then were replated at a density of $8.0 \times 10^{6}$ cells per $100 \mathrm{~mm}^{2}$ dish coated with poly-D-lysine $(10 \mu \mathrm{g} / \mathrm{ml})$ and Matrigel (Collaborative Research, Bedford, MA). The NT2N cells were maintained in DMEM HG with 5\% fetal bovine serum (FBS) and with penicillin/streptomycin with mitotic inhibitors $(1 \mu \mathrm{M}$ cytosine arabinoside, $10 \mu \mathrm{M}$ fluorodeoxyuridine, and $10 \mu \mathrm{M}$ uridine) for $4-6$ weeks or until $\sim 95 \%$ of the cells acquired the phenotype of neurons (Pleasure et al., 1992; Pleasure and Lee, 1993).

Phosphatase inhibitors. Phosphatase inhibitors were stored at $-70^{\circ} \mathrm{C}$ in small aliquots as concentrated stock solutions dissolved in 1\% dimethylsulfoxide (DMSO). They included the following aliquots: $500 \mu \mathrm{M}$ okadaic acid (OK), $100 \mu \mathrm{M}$ calyculin A (CL-A), and $500 \mu \mathrm{M}$ 1-norokadone, an inactive analog of OK (LC Labs, Woburn, MA). The properties of these reagents have been described in several previous reports (Bialojan and Takai, 1988; Cohen et al., 1989, 1990; Ishihara et al., 1989; Gurland and Gundersen, 1993; Matsuo et al., 1994; Sontag et al., 1995, 1996; Merrick et al., 1996).

Isolation of tubulin and tau from NT2N cells. Total tubulin was extracted from NT2N cultures by scraping the cells in ice-cold reassembly (RA) buffer (0.1 2-[N-morpholino]ethanesulfonic acid, $0.5 \mathrm{mM} \mathrm{MgSO}_{4}, 1$ mM EGTA, and $2 \mathrm{~mm}$ dithiothreitol, $\mathrm{pH} 6.8$ ) containing a mixture of protease inhibitors ( $2 \mathrm{~mm}$ phenylmethylsulfonyl fluoride, $20 \mathrm{~mm} \mathrm{NaF}, 0.5$ mM sodium orthovanadate, and $N$-tosyl-L-phenylalanine chloromethyl ketone, $N \alpha$ - $p$-tosyl-L-lysine chloromethyl ketone, leupeptin, pepstatin, and soybean trypsin inhibitor each at $10 \mu \mathrm{g} / \mathrm{ml}$ ). After incubation on ice for $10 \mathrm{~min}$, the cells were sonicated, and the supernatants were collected after centrifugation at $100,000 \times g$ for $20 \mathrm{~min}$ at $4^{\circ} \mathrm{C}$.

Soluble tubulin and insoluble MT polymers were obtained by scraping the cultures in $1 \mathrm{ml}$ of $37^{\circ} \mathrm{C}$ MT stabilization buffer, i.e., RA buffer containing $2 \mathrm{~mm}$ GTP and $20 \mu \mathrm{M}$ taxol to stabilize MTs (Schiff et al., 1979; Vallee, 1982) plus $0.1 \%$ (v/v) Triton X-100, 2 mm dithiothreitol, and a mixture of protease and phosphatase inhibitors. Taxol was a gift from Dr. V. Narayanan (Drug Synthesis and Chemistry Branch, Division of Cancer Treatment, National Cancer Institute). This scraped culture material was then homogenized in a glass homogenizer and centrif uged at $100,000 \times g$ for $20 \mathrm{~min}$ at $30^{\circ} \mathrm{C}$, generating a supernatant fraction containing soluble tubulin and a pellet fraction containing MT polymers.

In a similar manner, tau bound to pelleted MTs was separated from unbound tau that partitioned in the supernatant with soluble tubulin. Cultures were scraped into MT stabilization buffer, homogenized, and centrifuged as described above. The supernatant was boiled for $10 \mathrm{~min}$; the pellet was resuspended in ice-cold RA buffer containing $0.75 \mathrm{M} \mathrm{NaCl}$, was sonicated to release the bound tau from the MTs, and then was boiled for $10 \mathrm{~min}$. After both fractions were boiled, the samples were centrifuged again to generate heat-stable tau-enriched samples that were then concentrated by centrifugation through Amicon Microcon-10 spin columns. Finally, fetal human brain tau was used as a control sample in some of the studies of tau from the NT2N cells, and these fetal tau proteins were isolated from autopsy-derived prenatal human brains as described (Bramblett et al., 1992).

Western blot analysis. Protein samples were separated by SDS-PAGE and then electroblotted onto nitrocellulose membranes for Western blot studies. Antibody binding was quantified using ${ }^{125} \mathrm{I}$-labeled goat antimouse $\mathrm{IgG}$ for mouse monoclonal antibodies (mAbs) and ${ }^{125} \mathrm{I}$-labeled protein A for rabbit polyclonal antisera (Bramblett et al., 1992; Matsuo et al., 1994; Mawal-Dewan et al., 1994) and then exposing the nitrocellulose membranes to PhosphorImager plates. Quantification was performed with the IMAGEQUANT software provided with the PhosphorImager (Molecular Dynamics, Sunnyvale, CA), and these experiments were repeated at least three times. Protein analysis was performed using Coomassie blue as a dye reagent with bovine serum albumin as the standard (Pierce, Rockford, IL). For nonquantitative immunoblotting, antibody binding was detected with the peroxidase-anti-peroxidase method using diaminobenzadine as a substrate (Lee et al., 1991) or with Enhanced Chemiluminescence (DuPont NEN)

Antibodies. The anti-tubulin antibodies used were anti-Glu-tubulin antisera, which was a gift from Drs. C. Bulinski and G. Gundersen (Columbia University) (Gundersen et al., 1984); the anti-Tyr-tubulin antibody known as TUB-1A2 (Kreis, 1987) and the anti-acetylated tubulin antibody known as 6-11b-1 (Piperno and Fuller, 1985; Piperno et al., 1987), which were purchased from Sigma (St. Louis, MO); the anti- $\alpha$-tubulin and anti- $\beta$ tubulin mAbs (Blose et al., 1984), which were purchased from Amersham (Boston, MA); and the anti-Tyr-tubulin antibody known as YL1/2 (Kilmartin et al., 1982), which was purchased from Accurate Chemicals (Westbury, NY). Two phosphate-independent anti-tau mAbs used were T14 and T46 (Kosik et al., 1988; Trojanowski et al., 1989), one of which (T46) recognizes an epitope located at the $\mathrm{C}$ terminus of tau that is shared by the microtubule-associated protein (MAP) known as MAP2c (Kosik et al., 1988; Ksiezak-Reding et al., 1990). Two phosphate-dependent anti-tau antibodies that recognize PHFtau also used were the T3P antiserum (Lee et al., 1991) and the PHF1 mAb, which was kindly provided by Dr. P. Davies (Albert Einstein College of Medicine) (Greenberg et al., 1992; Otvos et al., 1994). Other antibodies used here were the mAb AP14 (Geisert et al., 1990), which is specific for MAP2 and was donated by Dr. L. Binder; the mAb HO14 (Pleasure et al., 1990), which is specific for highly phosphorylated forms of the midsize neurofilament (NF-M) subunit; the $\mathrm{mAb} 9-1 \mathrm{E} 10$, which is specific for the growth-associated protein (GAP) known as GAP-43 (Goslin and Banker, 1990); an anti-PP2A antibody to the catalytic subunit of PP2A, which was a gift from Dr. B. Hemmings (Miesscher Institute, Basel, Switzerland); and an antiserum to the catalytic subunit of protein phosphatase 1 (PP1), which was purchased from Upstate Biotechnology (Lake Placid, NY).

Indirect immunofluorescence. For the immunofluorescence studies, NT2N cells were grown on glass coverslips (25 mm in circumference) using the method described by Goslin and Banker (1991) with minor changes. NT2N cells that were plated on glass coverslips (at a density of $\sim 0.2 \times 10^{6}$ cells per coverslip) were cocultured with a feeder layer of NT2 cells that were plated on the bottom of the well. Three drops of paraffin were placed at the outer edge of each coverslip (coated previously with poly-D-lysine and Matrigel) to support the coverslips with the NT2N cells above the feeder layer of NT2 cells at the bottom of the wells during coculture. The NT2N cells were maintained in culture as described above for 3-4 weeks to allow the establishment of polarity as monitored by the segregation of MAP2 to the somatodendritic compartment and of highly phosphorylated NF-M to the axon using immunofluorescence methods (Pleasure et al., 1992; Bramblett et al., 1993). Immunofluorescence was performed on cultures that were washed with PBS and fixed according to one of two protocols. In the first procedure, cells were fixed with methanol at $-20^{\circ} \mathrm{C}$ for $10 \mathrm{~min}$, allowed to dry at room temperature, and rehydrated in PBS. In the second procedure, cells were fixed with $2 \%$ paraformaldehyde and $0.05 \%$ gluteraldehyde in PHEM buffer (60 mM 1,4-piperazinediethanesulfonic acid, $20 \mathrm{~mm}$ HEPES, 10 mM EGTA, and $1 \mathrm{~mm} \mathrm{MgSO}_{4}$ ) (Bramblett et al., 1993), rinsed with PBS, extracted with $0.1 \%$ Triton X-100 in PHEM buffer, washed with PBS, rinsed with $0.15 \mathrm{M}$ glycine, $\mathrm{pH} 7.4$, to quench the gluteraldehyde autofluorescence, and washed with PBS. The cultures were then incubated overnight at $4^{\circ} \mathrm{C}$ with a primary antibody, and bound antibody was detected with a secondary antibody (donkey anti-mouse, anti-rabbit, or anti-rat) coupled to FITC or to Texas Red (Jackson ImmunoResearch, West Grove, PA).

Transmission and immunoelectron microscopy. Cultures of NT2N cells were either untreated or treated with $50 \mathrm{~nm} \mathrm{CL-A} \mathrm{for} \mathrm{5,} \mathrm{15,} \mathrm{and} 60 \mathrm{~min}$ and were prepared for transmission electron microscopy (EM) and immuno-EM as described (Baas and Black, 1990; Baas et al., 1991; Lee et al. 1991). Cultured NT2N cells were washed with PBS at $37^{\circ} \mathrm{C}$ and were fixed for $1 \mathrm{hr}$ at $37^{\circ} \mathrm{C}$ in $0.1 \mathrm{M}$ cacodylate buffer, $\mathrm{pH} 7.0$, containing $2 \%$ gluteraldehyde and tannic acid at $2 \mathrm{mg} / \mathrm{ml}$. The cultures were rinsed three times with $0.1 \mathrm{M}$ cacodylate buffer, post-fixed for $30 \mathrm{~min}$ in $1 \%$ osmium tetroxide, rinsed once in $0.1 \mathrm{M}$ cacodylate buffer, rinsed three times in $0.05 \mathrm{~m}$ maleate buffer, $\mathrm{pH} 5.2$, stained for $10 \mathrm{~min}$ in $1 \%$ uranyl acetate in $0.05 \mathrm{M}$ maleate buffer, $\mathrm{pH} 6.0$, rinsed three times with $0.05 \mathrm{M}$ maleate buffer, $\mathrm{pH} 5.2$, dehydrated in an ascending series of ethanols, and embedded in Epon. Embedded samples were stained for $60 \mathrm{~min}$ at $60^{\circ} \mathrm{C}$ with $1 \%$ toluidine blue in $1 \%$ borax (Baas and Black, 1990) to visualize the axons and to ensure that thin sections were taken from areas enriched for axons as confirmed by phase-contrast photos of the trimmed block before sectioning. Thin sections cut parallel to the substratum were 
stained with uranyl acetate and lead citrate. For the immuno-EM studies, CL-A-treated and untreated NT2N cells were fixed, extracted with detergent, and incubated with primary antibodies exactly as described above for indirect immunofluorescence. The bound primary antibody was visualized with a goat anti-rabbit or anti-rat IgG secondary antibody conjugated to $5 \mathrm{~nm}$ gold particles (Amersham). The sections were then viewed with a Hitachi H-600 electron microscope (Nissei Sangyo America, Gaithersburg, MD).

Studies of the association of PP1 and PP2A with MTs. These studies were performed using rat brain- and NT2N cell-derived MTs. Rat brain MTs were obtained by homogenizing fresh adult rat brain in two volumes of ice-cold RA buffer plus protease inhibitors in a glass homogenizer and by centrifuging at $10,000 \times g$ for $20 \mathrm{~min}$ at $4^{\circ} \mathrm{C}$. The supernatant was decanted and centrifuged again at $100,000 \times g$ for $60 \mathrm{~min}$ at $4^{\circ} \mathrm{C}$. The resulting supernatant was incubated in the presence of $1 \mathrm{mM}$ GTP and 20 $\mu \mathrm{M}$ taxol at $37^{\circ} \mathrm{C}$ for $20 \mathrm{~min}$ to promote the assembly of MT polymers. MTs were then pelleted through a 5\% sucrose cushion at $30,000 \times g$ for $30 \mathrm{~min}$ at $30^{\circ} \mathrm{C}$, and protein concentrations were determined as described above. Supernatant and MT pellet fractions were then analyzed for the presence of MT-associated PP2A and PP1 by Western blotting as described above.

MTs from NT2N cells were obtained by scraping cells from 10-15 100 $\mathrm{mm}^{2}$ dishes into $0.5-1.0 \mathrm{ml}$ of ice-cold PHEM buffer plus $0.2 \%$ Triton $\mathrm{X}-100$ and protease inhibitors and by homogenizing. The samples were centrifuged at $100,000 \times g$ for $60 \mathrm{~min}$ at $4^{\circ} \mathrm{C}$. The resulting high-speed supernatant was incubated with GTP and taxol as described above, and the MTs were pelleted by centrifugation as described above.

Presentation of results from studies performed using $C L-A$ and $O K$. In the studies described below, similar or nearly identical results were obtained after treatment of the NT2N cells with CL-A and OK. Hence, for simplicity, only the results obtained with either CL-A or OK are described in each of the following sections, and in most of the experiments summarized, the results obtained with CL-A are described in detail.

\section{RESULTS}

Inhibitors of PP2A and PP1 increase tau phosphorylation and decrease the binding of tau to MTs in NT2N cells

To determine the effects of inhibitors of PP2A and PP1 on tau phosphorylation and on the binding of tau to MTs, we treated NT2N cells with $50 \mathrm{~nm}$ CL-A for varying lengths of time. Not surprisingly, low concentrations of CL-A resulted in increased tau phosphorylation as indicated by a retardation in the electrophoretic mobility of tau (Fig. $1 \mathrm{~A}$, compare lane $0 \mathrm{~S}$ with lanes $15 \mathrm{~S}$ and $30 S$ ) and by an increase in the immunoreactivity of tau detected by phosphorylation-dependent antibodies such as T3P and PHF1 (data not shown) as well as by other phosphorylationdependent antibodies to PHFtau (Merrick et al., 1996). In addition, the binding affinity of tau for MTs progressively decreased (Fig. $1 \mathrm{~A}$, compare $S$ and $P$ lanes) after longer exposure to CL-A. Indeed, quantitative immunoblot analysis revealed that $\sim 40 \%$ of tau was recovered in the soluble fraction in control cultures, whereas after $15 \mathrm{~min}$ of treatment with CL-A, $\sim 90 \%$ of the tau protein is located in the soluble fraction (Fig. $1 A, B$ ). Because similar results were obtained with $\mathrm{OK}$, these data indicate that treatment of NT2N cells with inhibitors of PP2A and PP1 increases the phosphorylation state of tau and decreases the binding of tau to MTs.

\section{Preferential destruction of axons in NT2N neurons treated with phosphatase inhibitors}

During the course of treatment of NT2N neurons with CL-A, we noted that a subset of neuronal processes were rapidly and selectively destroyed. Because NT2N cells develop a large number of polarized processes that exhibit the morphological and molecular properties of either axons or dendrites (Pleasure et al., 1992), we

\section{Effect of CL-A on Tau Phosphorylation and MT Binding}

\section{A. $\mathbf{T 1 4} / 46$}

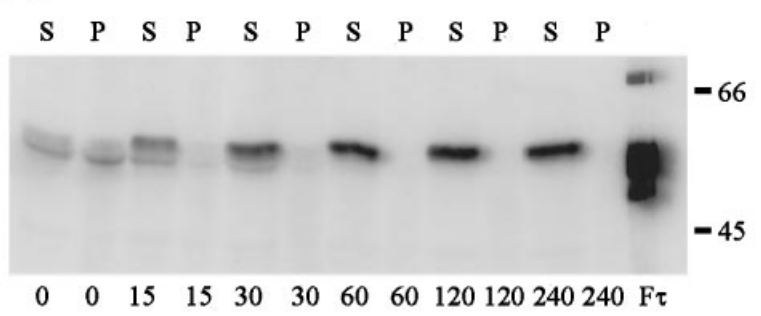

Treatment Time (min)

\section{B. Tau Distribution}

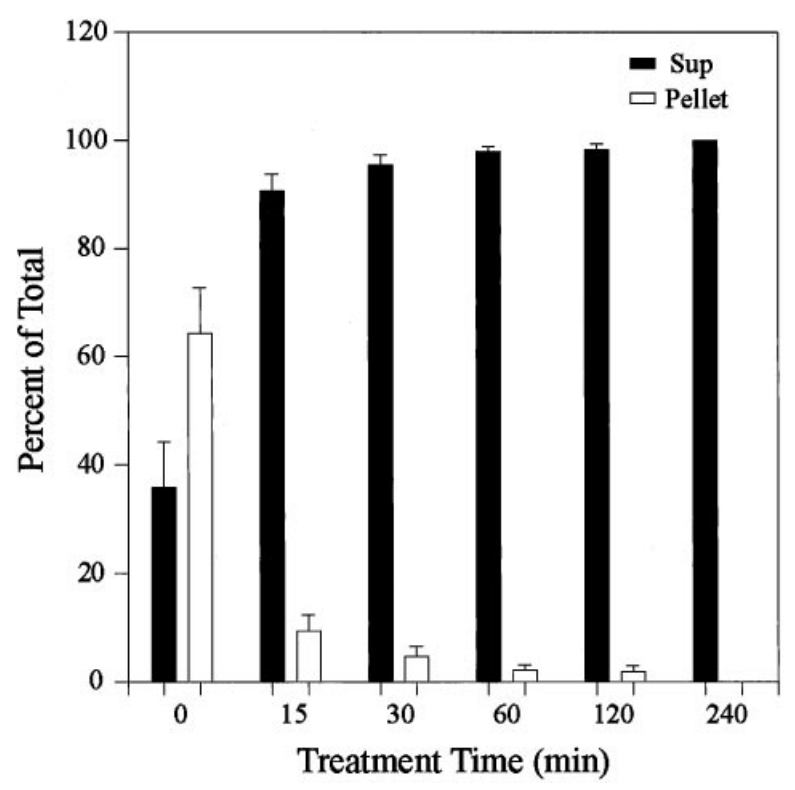

Figure 1. A, Effects of CL-A on tau phosphorylation and on MT binding in NT2N cells. NT2N neurons were treated with $50 \mathrm{nM}$ CL-A for the times (in minutes) indicated below each lane and were processed to detect unbound tau in the supernatant $(S)$ and tau bound to MTs in the pellet $(P) . S$ and $P$ fractions of treated and untreated NT2N cells were analyzed in Western blots using a mixture of two anti-tau (T14, T46) mAbs. B, Tau distribution between supernatants (Sup) and pellets. The levels of tau in the supernatants and pellets were quantified, and the values are expressed as the percentage of the total tau level for each time point. Data represent mean $\pm \operatorname{SEM}(n=5)$.

sought to determine whether axons or dendrites were selectively vulnerable to CL-A-induced degeneration. To do this, we used data from previous studies showing that the somatodendritic domain of neurons is rich in MAP2 (Bernhardt and Matus, 1984; Pleasure et al., 1992), whereas axons are rich in highly phosphorylated neurofilament proteins (Pleasure et al., 1992). Thus, we performed single and double label indirect immunofluorescence studies using the AP14 mAb to MAP2 and the HO14 mAb to highly phosphorylated NF-M to demonstrate that the NT2N cells 

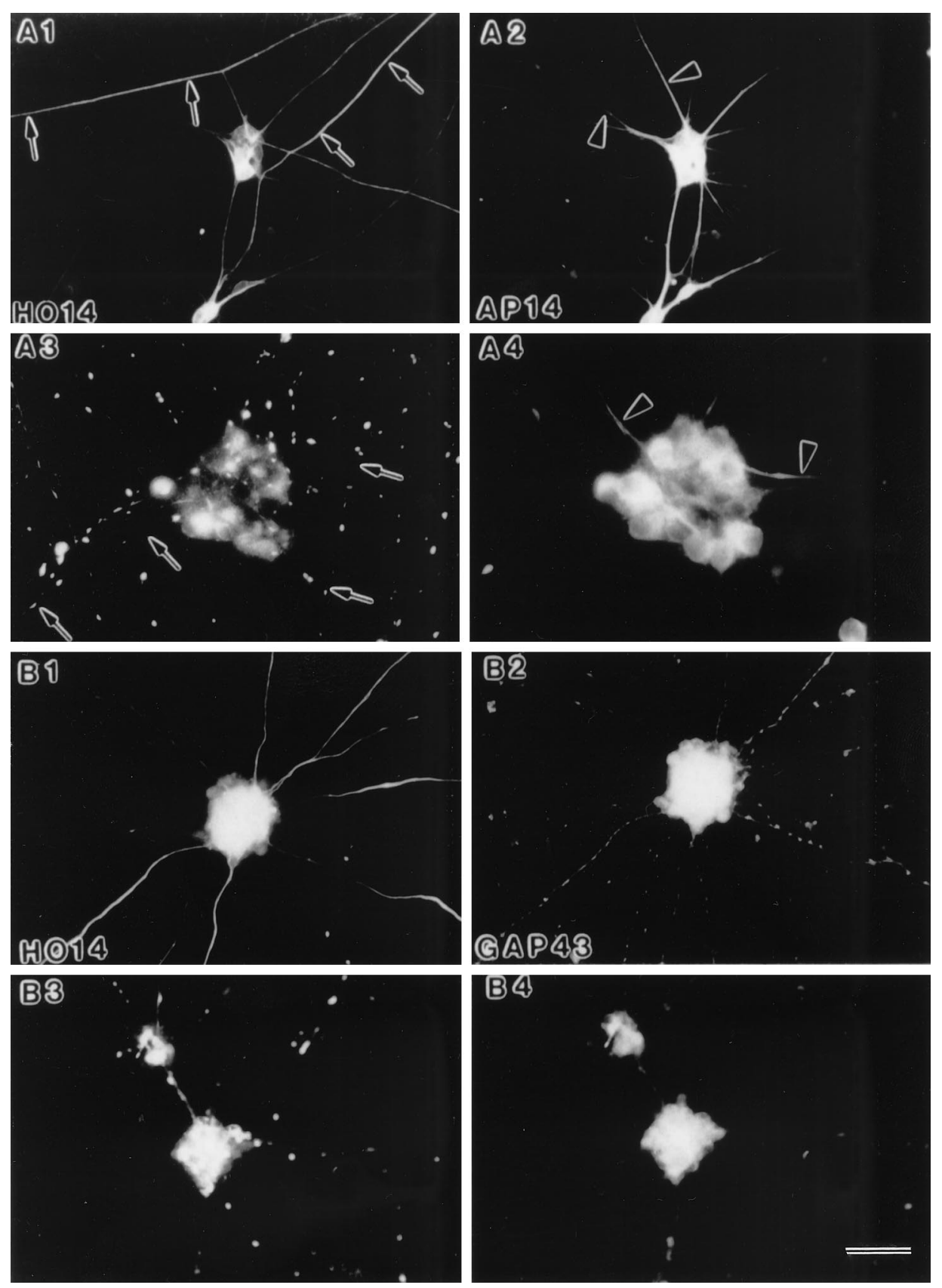

Figure 2. Double-label immunofluorescence of CL-A-treated NT2N cells. Pairs of antibodies were used to double-label untreated $(A 1, A 2, B 1, B 2)$ and $C L-A$-treated (50 nM for $60 \mathrm{~min} ; A 3, A 4, B 3, B 4$ ) cultures. Cultures were double-labeled with $\mathrm{HO} 14$ mAb to highly phosphorylated NF-M in axons $(A 1, A 3)$ and with AP14 mAb to MAP2 in perikarya and dendrites $(A 2, A 4)$. Arrows point to axons, whereas arrowheads identify dendrites. Note that all axons are destroyed in treated cultures, whereas some dendrites remain intact. Similar cultures were stained with $\mathrm{HO} 14$ mAb $(B 1, B 3)$ and with 9-1E10 $\mathrm{mAb}$, which recognizes GAP-43 $(B 2, B 4)$. Again, note the preferential degeneration of axons. Scale bar, $100 \mu \mathrm{m}$. extended highly polarized dendrites and axons, respectively (Fig. $2 A 1, A 2)$. When similar studies were performed on the NT2N cells treated with CL-A, HO14 mAb confirmed that axons rapidly degenerated (Fig. 2A3). Although the number of MAP2-positive dendrites seemed to diminish, many remained smooth and undisrupted (Fig. 2A4).

To confirm and extend these observations, we double labeled the NT2N cells before and after treatment with CL-A using $\mathrm{HO} 14 \mathrm{mAb}$ and an antibody to GAP-43, a protein that is expressed in axons during periods of active growth and is found in association with vesicular transport. In untreated cells, the antiGAP-43 antibody stained axons like the HO14 mAb but displayed a punctate pattern of immunoreactivity [compare HO14 staining (Fig. 2B1) with GAP-43 staining (Fig. 2B2)]. However, after treatment with CL-A, both the HO14 and GAP-43 positive axons of the NT2N cells rapidly degenerated (Fig. 2B3,B4).

\section{Phosphatase inhibitors decrease Glu-tubulin levels and increase Tyr-tubulin levels in NT2N cells}

We examined phosphatase inhibitor-induced changes in the different posttranslationally modified forms of MTs by treating NT2N cultures with $100 \mathrm{~nm} \mathrm{OK}$ for up to $4 \mathrm{hr}$. These studies showed that the levels of Glu-tubulin and acetylated-tubulin (Actubulin) in the more stable pool of MTs were dramatically reduced with progressively longer treatment times (Fig. 3A, C, compare lane 1 with lane 5). Quantitative analysis of Western blots revealed that after $4 \mathrm{hr}$ of treatment, Glu-tubulin immunoreactivity was only $20 \%$ relative to untreated cultures, indicating that the level of stable MTs had been reduced by $80 \%$. The levels of Tyr-tubulin concomitantly increased (Fig. 3B, compare lane 1 with lanes 4 and 5) by $55 \%$ after 4 hr of treatment. However, we cannot directly compare the changes detected by one antibody 


\section{A. Glu Tubulin}
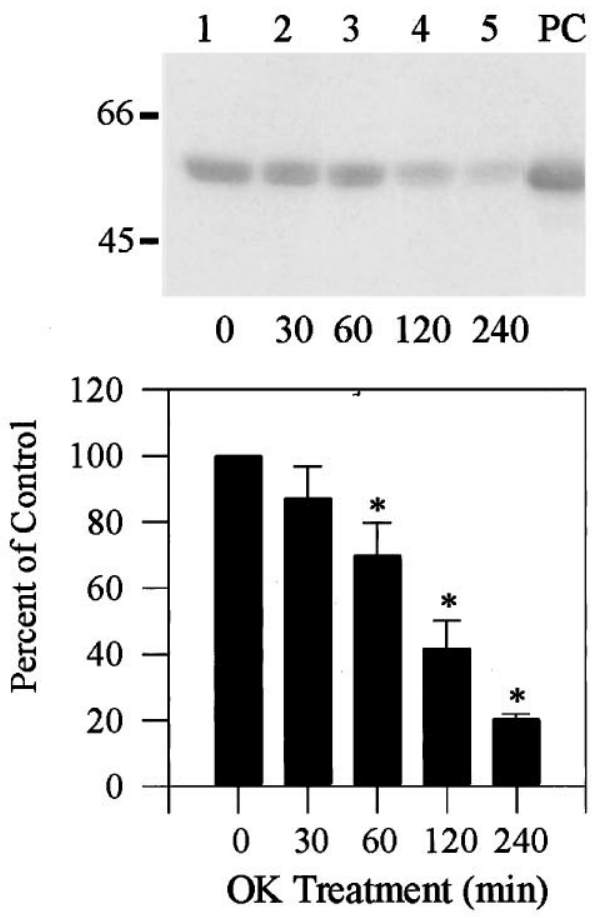

C. Ac Tubulin

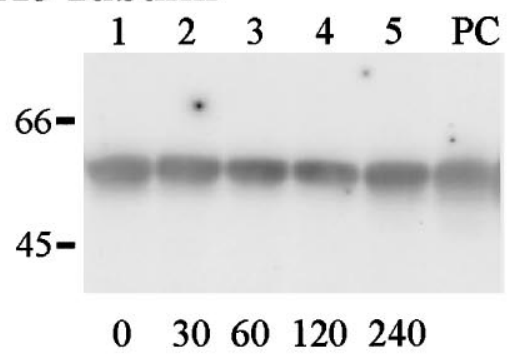

fects of OK treatment on Glu- and Tyr-tubulin levels in NT2N neurons. NT2N cultures were treated with 100 nM OK for up to $4 \mathrm{hr}$ and analyzed by quantitative Western blotting using antibodies specific for modified $\alpha$-tubulin: $A$, Glu-tubulin; $B$, Tyr-tubulin; $C$, Ac-tubulin; $D, \beta$-tubulin. OK decreased Glu- and Ac-tubulin levels and increased Tyr-tubulin levels. Note that the $\beta$-tubulin immunoreactivity is constant indicating that total tubulin levels are unaffected. Values for each time point were calculated as the percentage of untreated cultures and illustrated in the bar graphs below each set of Western blots. Data represent mean $\pm \operatorname{SEM}(n=4$; asterisks indicate significance, ${ }^{*} p<0.005$ and $*^{*} p<0.05$; Student's $t$ test, independent pairs).

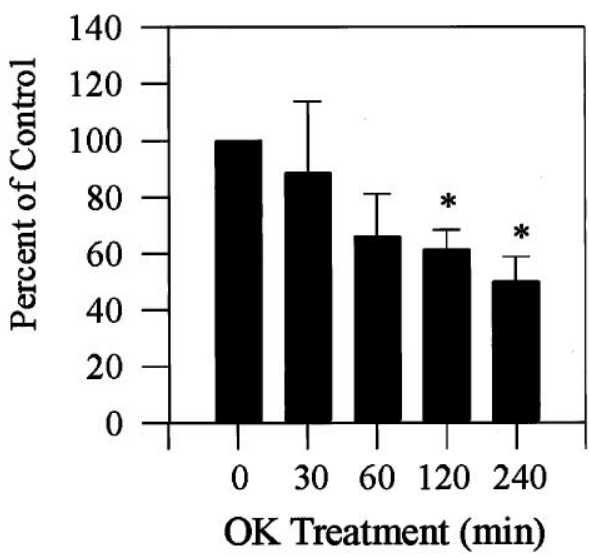

\section{B. Tyr Tubulin}
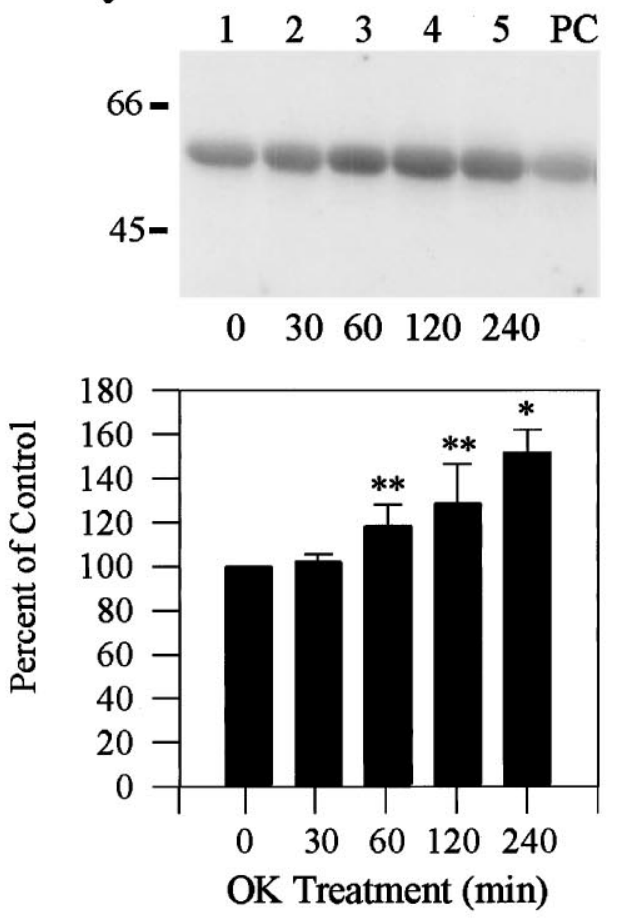

D. Beta Tubulin

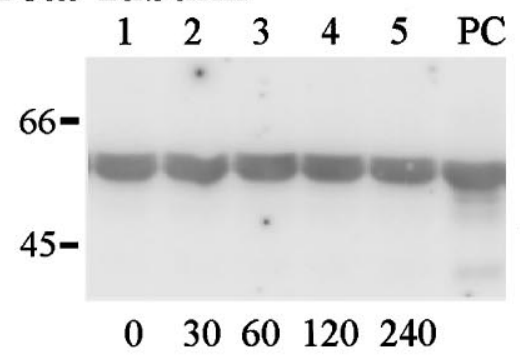

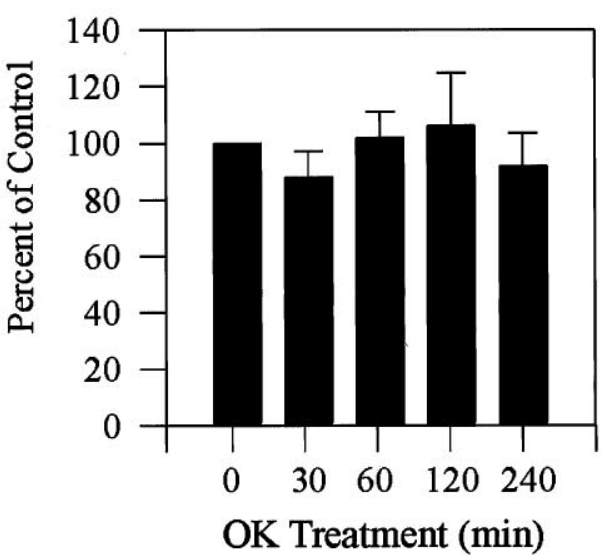

with the changes observed for the other because of the different affinities of these antibodies. Because acetylation is another posttranslational modification of $\alpha$-tubulin that correlates with the stabilization of MTs, it was not surprising that OK treatment of the NT2N cells for $4 \mathrm{hr}$ resulted in a $40 \%$ decrease in Ac-tubulin levels (Fig. 3C). Because the levels of tubulin did not change in these experiments (as monitored with the anti- $\beta$-tubulin antibody), it is unlikely that tubulin synthesis and turnover were altered significantly by $\mathrm{OK}$ treatment (Fig. 3D). To validate the effects of $\mathrm{OK}$ further, we treated NT2N cultures with 
1-norokadone, an inactive analog of OK, but this analog did not reduce the levels of Glu-tubulin in the NT2N cells. Taken together, these findings indicate that inhibitors of PP2A and PP1 induce a decrease in the pool of stable MTs followed by a rapid retyrosination of Glu-tubulin resulting in an increase in the more labile Tyr-tubulin.

\section{Phosphatase inhibitors depolymerize Glu-MTs but not Tyr-MTs}

To determine whether the reduction in Glu-tubulin levels was caused by a selective reduction in Glu-MTs, we treated NT2N cells with CL-A and processed the cultures to analyze soluble and insoluble cytoskeletal proteins in the NT2N cells and to monitor changes in the distribution of tubulin between protomers and MT polymers. Inhibition of protein phosphatases resulted in decreased Glu-MTs in the insoluble cytoskeletal fraction, consistent with a breakdown or disassembly of the stable pool of MTs (Fig. $4 A$, compare lanes 1 and 2 with lanes 11 and 12 ). Furthermore, quantitative analysis indicated that in untreated cultures $86 \%$ of Glu-tubulin was present as Glu-MTs and that after $4 \mathrm{hr}$ of treatment with CL-A only $34 \%$ of Glu-MTs remained in the insoluble cytoskeletal fraction (Fig. $4 E, G$ ). Notably, this decrease in Glu-MTs is not compensated for by an increase in the soluble Glu-tubulin. Instead, there is a decrease in soluble Glu-tubulin, and this indicates that when Glu-MTs depolymerize, the Glutubulin released from these polymers is rapidly retyrosinated (see below and Fig. 4B). Thus, these data suggest that inhibition of PP1 and PP2A induces a depolymerization of stable Glu-MTs and that the tubulin subunits released from these polymers quickly undergo retyrosination.

Consistent with this view, Figure $4 B$ shows that Tyr-tubulin immunoreactivity increases in the supernatant fractions (Fig. $4 B$, compare lane 1 with lanes 9 and 11) of CL-A-treated NT2N cells, and that the Tyr-tubulin immunoreactivity in the pellet fraction remains approximately the same for each time point (Fig. $4 B$, compare lane 2 with lanes 10 and 12). Furthermore, quantitative analysis showed that in control cultures $60 \%$ of Tyr-tubulin was soluble and $40 \%$ was polymerized into MTs (Fig. 4B). However, after $4 \mathrm{hr}$ of CL-A treatment, total Tyr-tubulin immunoreactivity (Fig. $4 B, S$ plus $P$ ) is increased, as reflected by a dramatic increase $(\sim 193 \%)$ in soluble Tyr-tubulin monomers (Fig. $4 G)$. Significantly, there is no change in Tyr-MTs in the pellet fraction.

Because OK and CL-A treatment leads to the selective disassembly of stable MTs in the NT2N cells, this should result in a decrease in the levels of total $\alpha$-tubulin-containing MTs in the pellet fraction with a concomitant increase in $\alpha$-tubulin in the soluble fraction, and this is illustrated in Figure $4 D$ (compare lane 2 with lanes 10 and 12 and lane 1 with lanes 9 and 11). The percentage of $\alpha$-tubulin-containing MTs decreased from $80 \%$ for control cultures to $20 \%$ for cultures treated with CL-A for $4 \mathrm{hr}$ (Fig. $4 F, G$ ). However, the total signal of the soluble plus the cytoskeletal fractions for each time point showed no significant change, indicating that, as the amount of MTs in the pellet decreases, the soluble fraction of tubulin protomers increases, which is consistent with the notion that the decrease in MT polymer was not caused by the degradation of tubulin (also see Fig. $3 D$ ). Significantly, the effect of CL-A on Glu-tubulin and tau seems to follow a similar time course (Figs. 1, 4). Finally, if the inhibition of phosphatases induces the depolymerization of stable MTs, then the levels of Ac-tubulin (which also serves as a marker of stable MTs) should decrease as a result of CL-A treatment, and this finding is demonstrated in Figure $4 C$ (compare lane 2 with lanes 10 and 12). Because no Ac-tubulin is detected in the soluble fractions, deacetylation must be very rapid.

Taken together, these data indicate that inhibition of PP1 and PP2A results in the depolymerization of MTs and that this depolymerization is selective for the more stable pool of MTs. Furthermore, these data also suggest that the tubulin subunits released from the CL-A-induced depolymerization of Glu-MTs are rapidly retyrosinated and/or deacetylated, and that the ratelimiting step in this process is the depolymerization of the more stable MTs that are rich in Glu-tubulin.

\section{Phosphatase inhibitors induce rapid and selective destruction of axonal MTs}

To investigate the ultrastructural effects of phosphatase inhibitors on the NT2N cells, we used transmission EM to study CL-Atreated NT2N cells. To do this, we focused our EM studies on areas of the cultures that were the farthest away from cell body clumps in which axons are most abundant (Pleasure et al., 1992) (Fig. 2). The axons of untreated NT2N cells contained many long, uninterrupted MTs that were oriented parallel to the axolemma (Fig. 5A,B). However, after $5 \mathrm{~min}$ of treatment with CL-A, short fragments of MTs appeared that were oriented at various angles to the long axis of the axon, but the axolemma seemed to remain intact (Fig. 5C). Longer treatment with CL-A resulted in the degeneration of many of the axons. However, in those axons remaining, we observed an increase in the abundance of short MT fragments, a reduction in the number of intact MTs, and accumulations of amorphous material in the axoplasm (Fig. 5D). Thus, these data are consistent with the view that CL-A induces the breakdown of axonal Glu-rich MTs and that this breakdown may account for the preferential destruction of axons by CL-A described above.

\section{Phosphatase inhibitors reduce the abundance of Glu-MTs in axons}

To explore the basis of this axonal pathology in greater detail, we undertook immuno-EM studies to determine whether Glu-MTs in the axons of NT2N cells were affected by CL-A treatment. In untreated cultures, immunoreactive Glu-MTs were far more numerous than Tyr-MTs in axons (Fig. 6A,B), whereas the abundance of Glu-MTs and Tyr-MTs was similar in cell bodies (Fig. $6 E, F)$ and dendrites (data not shown). Varying the concentrations of the primary antibodies to Glu-tubulin and to Tyr-tubulin did not alter the distribution of the labeled MTs in axons. Specifically, the relative abundance of Glu-MTs remained far greater than that of Tyr-MTs (data not shown), and we never observed Glu-MT-rich segments existing in continuity with Tyr-MT-rich segments in individual MTs. Instead, immunogold particles demonstrated Glu-MTs over the entire length of individual MTs within the main shaft of axons. After treatment of the NT2N cells with CL-A, there was a reduction in the total number of axonal MTs, especially Glu-MTs, the most abundant pool of MTs in these axons (Fig. 6, compare $A, B$ with $C, D$ ). Given the similar abundance of Glu-MTs and Tyr-MTs in cell bodies and dendrites, the loss of Glu-MTs is not as apparent in cell bodies (Fig. 6, compare $E, F$ with $G, H)$. Thus, the selective degeneration of axons after treatment with CL-A may reflect the greater abundance of Glu-MTs in the axons of the NT2N cells.

\section{PP2A is associated with MTs in the NT2N cells}

Because CL-A and OK inhibit both PP1 and PP2A, we sought to determine which of these enzymes might be responsible for the decrease in Glu-MT levels described above by determining 


\section{Effect of CL-A on MT Polymerization}

\section{A. Glu Tubulin}

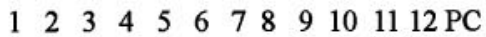

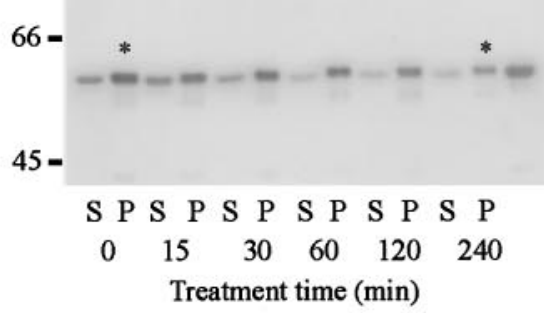

C. Ac Tubulin

$\begin{array}{lllllllllllll}1 & 2 & 3 & 4 & 5 & 6 & 7 & 8 & 9 & 10 & 11 & 12 & \mathrm{PC}\end{array}$

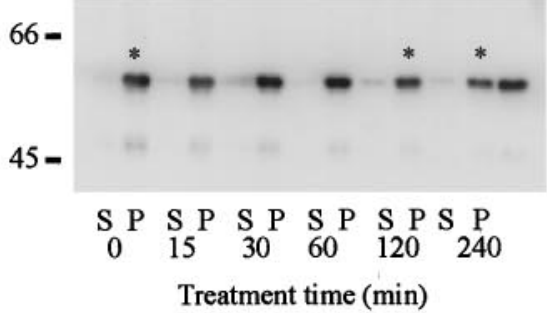

E. Glu Tubulin (P)

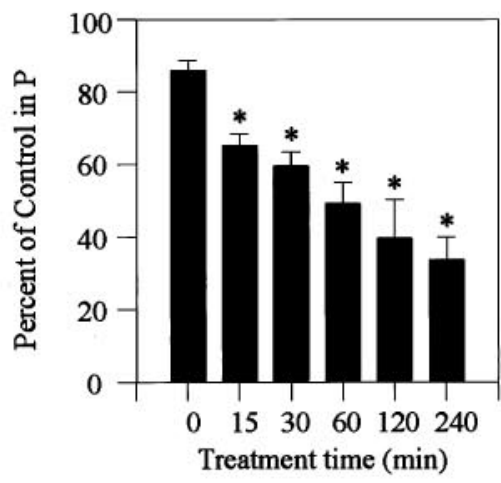

\section{B. Tyr Tubulin}

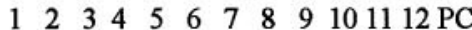

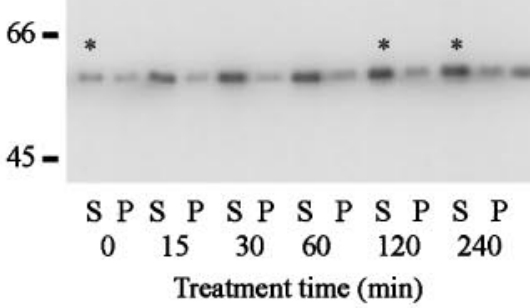

D. Alpha Tubulin

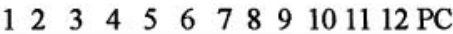

$66-$

$* * \quad * * * *$

$--\cdots-\cdots-\cdots+\cdots$

45 -

$$
\begin{array}{cccccc}
S_{0} P & \underset{15}{\text { S P }} & \text { S P } & \text { S P } & \text { S P } & \text { S P P } \\
\multicolumn{5}{c}{\text { Treatment time (min) }}
\end{array}
$$

\section{F. Alpha Tubulin (P)}

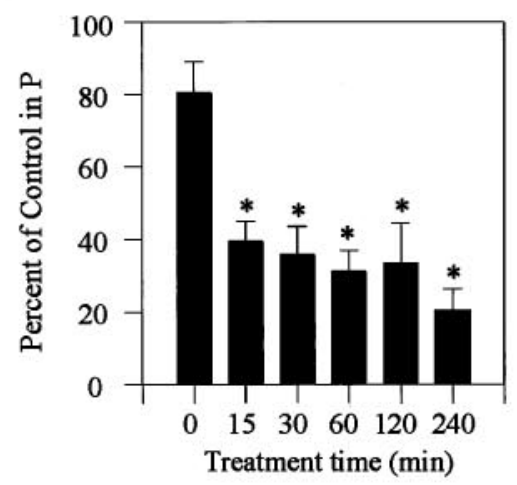

Figure 4. Effect of CL-A treatment on MT polymer levels in NT2N cells. NT2N cultures were treated with $50 \mathrm{~nm}$ CL-A for up to $4 \mathrm{hr}$, processed for soluble tubulin $(S)$ and MT polymers $(P)$, and analyzed by quantitative Western blotting: $A$, Glutubulin; $B$, Tyr-tubulin; $C$, Ac-tubulin; $D$, $\alpha$-tubulin. $E, F$, Bar graphs demonstrating the loss of stable Glu-MTs and the decrease of $\alpha$-MTs, respectively, from the pellets $(P)$ after treatment of NT2N cells with CL-A for the indicated times. The decrease in MTs was calculated as the amount of tubulin immunoreactivity in the pellet divided by total tubulin immunoreactivity in untreated NT2N cells. $G$, Bar graph showing the soluble tubulin remaining in the supernatant $(S)$ and the MT polymers recovered in the pellets $(P)$ for Glu-tubulin, Tyr-tubulin, Ac- tubulin, and $\alpha$-tubulin in untreated cultures and cultures treated with CL-A for $4 \mathrm{hr}$. Data represent mean $\pm \operatorname{SEM}(n=4$; asterisks in bar graphs indicate significance, ${ }^{*} p<0.005$; Student's $t$ test, independent pairs).

\section{G. Distribution of Tubulin and MT Polymers}

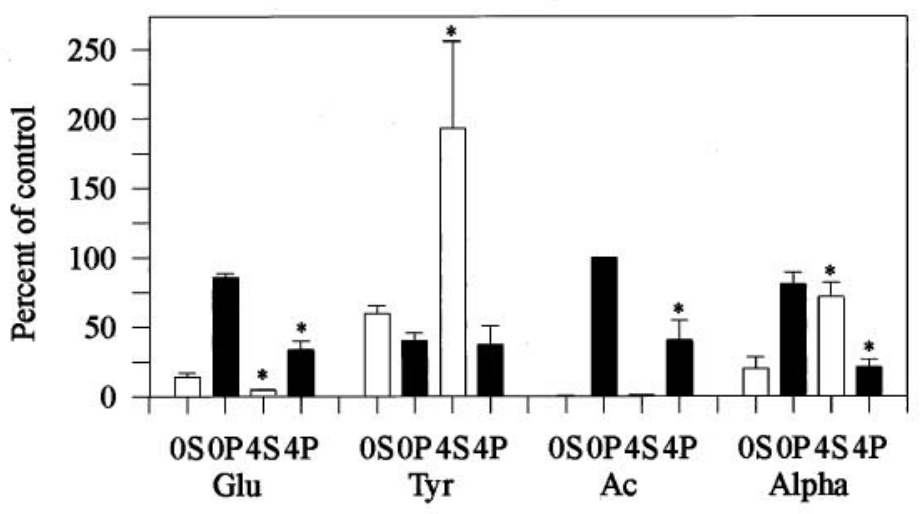

CL-A Treatment (h) 

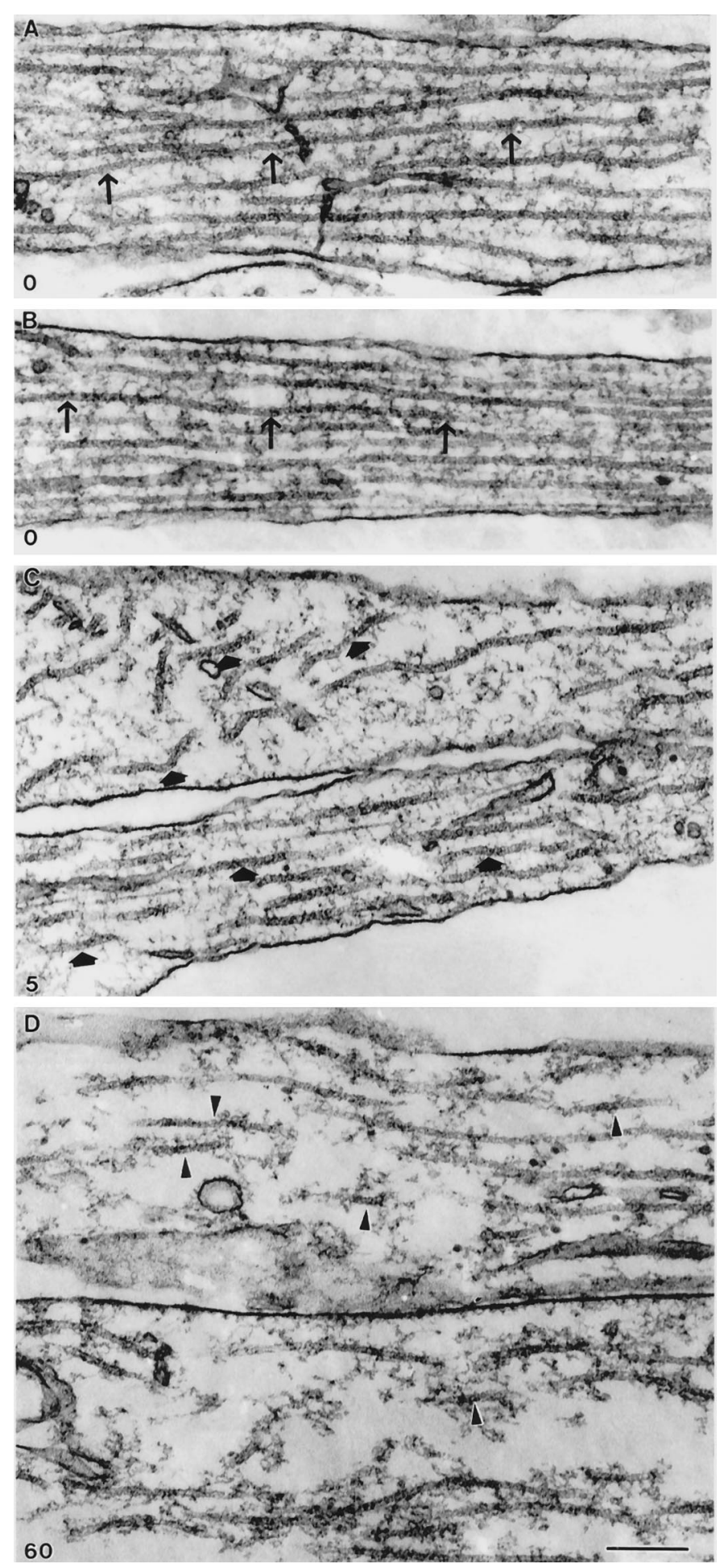

Figure 5. Electron micrographs of axonal MTs treated with CL-A. NT2N cultures were treated with $50 \mathrm{~nm} C L-A$ for $0 \min (A, B), 5 \mathrm{~min}(C)$, or $60 \mathrm{~min}(D)$ and analyzed by EM. Control cultures contain long, continuous MTs (arrows) of uniform orientation, and treated cultures contain many short MT fragments (arrowheads) oriented at various angles to the long axis of the axon. Scale bar, $100 \mathrm{~nm}$.

whether one or both of these phosphatases was closely associated with MTs in the NT2N cells. To address this question, we incubated high-speed supernatants from rat brain homogenates and from NT2N cells with taxol at $37^{\circ} \mathrm{C}$, and the MTs were pelleted by centrifugation. Consistent with the results of Sontag et al. (1995), we detected PP2A in association with pelleted MTs (Fig. $7 A, C)$, whereas PP1 was recovered only in the soluble fraction (Fig. 7B,D). Thus, these observations suggest that the inhibition of PP2A by the phosphatase inhibitors used here accounts for the alterations in tau and MTs described above.

\section{DISCUSSION}

In the studies reported here, we show that inhibition of PP1 and PP2A in cultured human neuron-like NT2N cells by OK and CL-A results in (1) the hyperphosphorylation of tau, (2) the decreased binding of tau to MTs, (3) the selective depolymerization of the more stable Glu-MTs, especially in axons, and (4) the rapid degeneration of axons. Furthermore, we also show that axons of NT2N cells contain more Glu-MTs than cell bodies and dendrites, which suggests that the abundance of Glu-MTs in axons may render these processes more vulnerable to rapid degeneration after treatment with $\mathrm{OK}$ and CL-A. However, we cannot rule out the possibility that phosphatase inhibitors may have a direct effect on axons. Although the precise sequence of events leading to these abnormalities remains to be elucidated, the demonstration here that PP2A (but not PP1) is closely associated with MTs in the NT2N cells leads us to infer that OK and CL-A induce the alterations described above by inhibiting a pool of MT-associated PP2A. Although the relevance of these findings to AD must be explored further, our data are consistent with growing evidence implicating the inactivation of PP2A in the formation of NFTs and in the degeneration of neurons in the AD brain (Goedert et al., 1992; Matsuo et al., 1994; Sontag et al., 1995, 1996).

The selective destruction of Glu-MTs (but not Tyr-MTs) in NT2N cells by OK or CL-A is in agreement with a previously published report demonstrating a complete breakdown of GluMTs in fibroblasts and in epithelial cells after treatment with the same inhibitors (Gurland and Gundersen, 1993). However, it was postulated by Gurland and Gundersen that PP1 but not PP2A is the phosphatase that regulates the stability of Glu-MTs. This hypothesis is based on the observation that CL-A (which is a more potent inhibitor of PP1 than is OK) is more effective in inducing the depolymerization of Glu-MTs. However, it is well known that the concentration of inhibitors needed to inhibit a specific phosphatase in intact cells depends on the actual concentration of the phosphatase in these different cell types. Often, high concentrations (micromolar) of these inhibitors are required for complete inhibition (Cohen et al., 1990). Thus, it may be difficult to identify definitively the specific phosphatase that is responsible for the observed effects based on pharmacological manipulation alone. Recently, PP2A has been shown to be capable of binding to MTs (Sontag et al., 1995). Our finding that the catalytic subunit of PP2A but not PP1 can be recovered bound to MTs in high-speed supernatants obtained from rat brain and NT2N cells suggests that the species of PP2A associated with MTs may be in a position to regulate the stability of MTs directly. However, it should be pointed out that a lack of association of PP1 does not mean that PP1 cannot regulate Glu-MT stability. Future studies using specific inhibitors of PP1 or PP2A could help resolve this issue.

Previous studies have demonstrated that the distribution of GluMTs varies for different cell types. For example, fibroblasts and epithelial cells exhibit a subpopulation of stable MTs that comprises exclusively Glu-MTs (Schulze, 1987). By contrast, individual 
GLU

$\mathbf{A X}(-)$
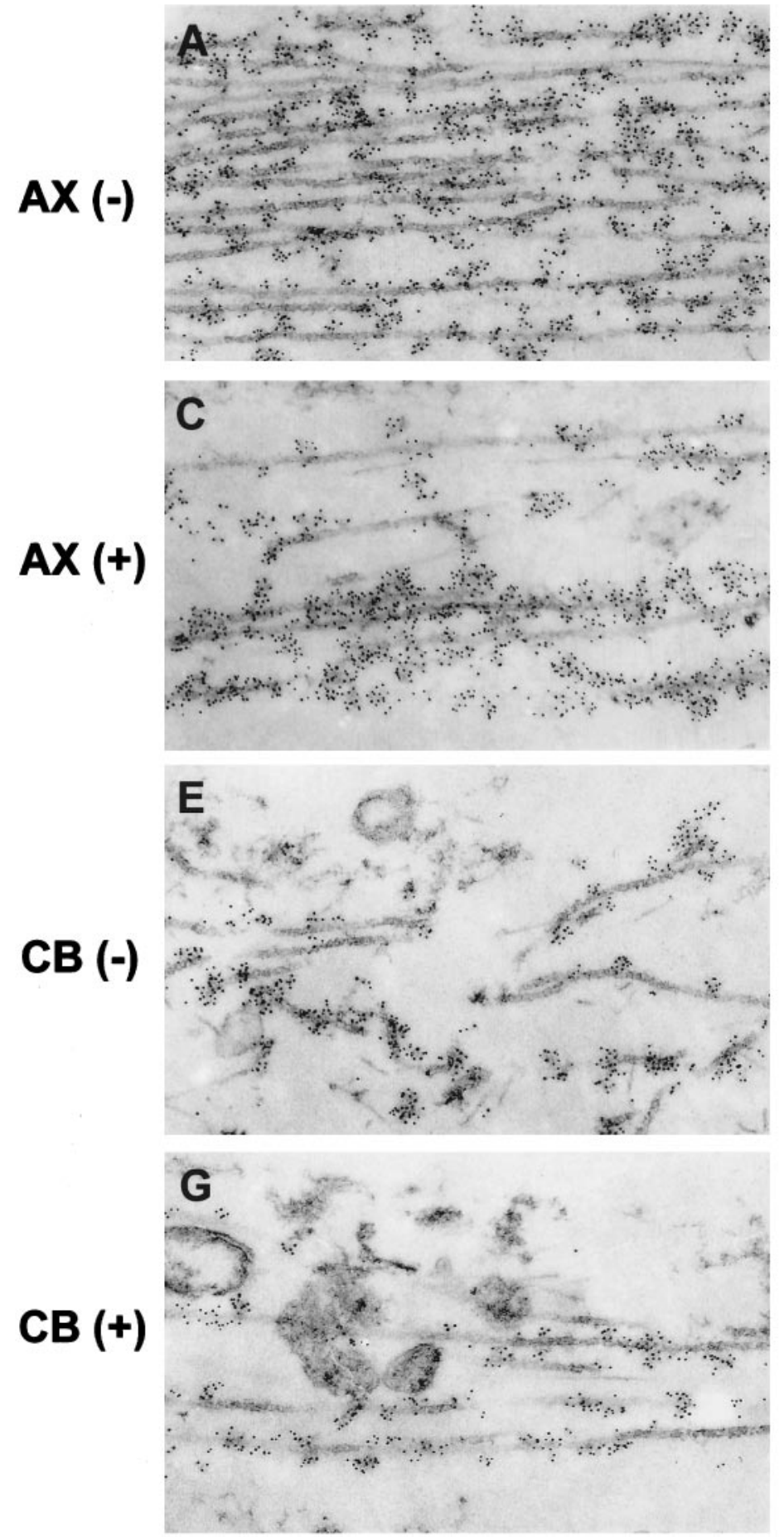

TYR
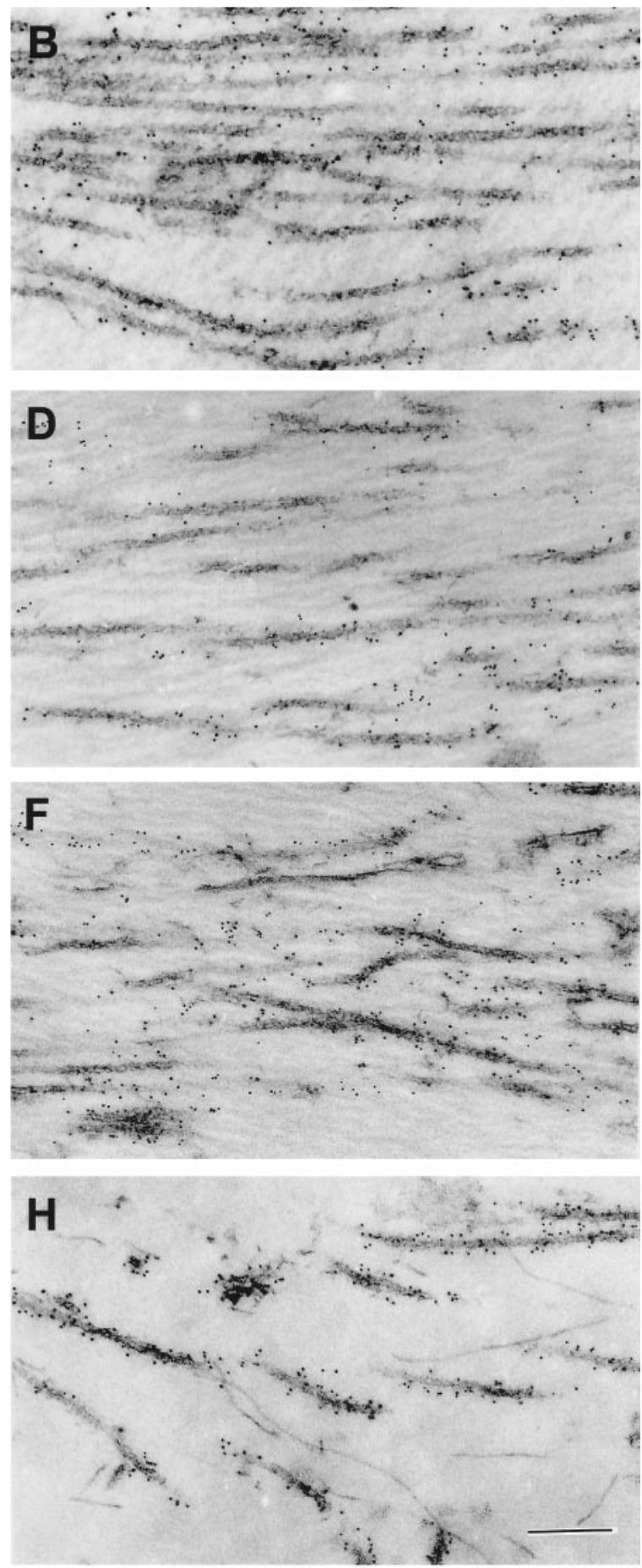

Figure 6. Immuno-EM of axonal and perikarya Glu-MTs and Tyr-MTs after treatment with CL-A. NT2N cells were treated with 50 nM CL-A for 0 $\min (A, B, E, F)$ or for $15 \min (C, D, G, H) . A, C, E, G$, Cells first immunolabeled with the anti-Glu-tubulin antibody and then with $5 \mathrm{~nm}$ gold-conjugated goat anti-rabbit IgG. $B, D, F, H$, Cells first incubated with the anti-Tyr-tubulin antibody and then with 5 nm gold-conjugated rabbit anti-rat IgG. $A X(-)$ and $A X(+)$ denote immunolabeling of untreated and CL-A-treated axonal MTs, whereas $C B(-)$ and $C B(+)$ represent immunolabeling of untreated and CL-A-treated MTs in neuronal perikarya. Scale bar, $100 \mathrm{~nm}$.

MTs in the main shafts of axons of sympathetic neurons are composed of a Glu-MT-rich segment located proximal to and in direct continuity with a Tyr-MT-rich domain such that stable and labile regions in the axon exist as distinct domains on individual
MTs (Baas and Black, 1990). Our immuno-EM analysis of the organization of Glu-MTs and Tyr-MTs in individual MTs in the main axonal shafts of NT2N cells suggests a third arrangement. Unlike those observed for non-neuronal cells and for sympathetic 


\section{Rat Brain}

A. PP2A

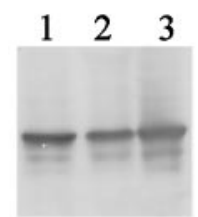

S P Tot
B. PP1

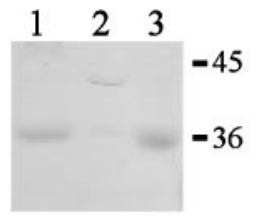

S P Tot

\section{NT2N Cells} C. PP2A

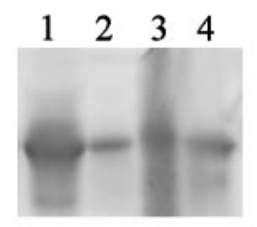

S P Std Tot

\section{PP1}

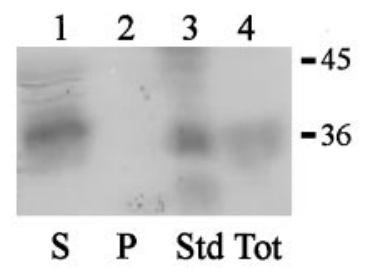

Figure 7. Association of PP2A but not PP1 with MTs. MTs were reassembled from either rat brain homogenates or homogenates of NT2N cells, and the association of PP1 and PP2A with MTs was examined by immunoblotting using antibodies to the catalytic subunit of PP2A $(A, C)$ or of PP1 $(B, D)$. In $A-D$, lane 1 contains soluble protein $(S)$, and lane 2 contains MT-associated proteins after taxol-driven polymerization $(P)$. Lane 3 in $A$ and $B$ and lane 4 in $C$ and $D$ contain total (Tot) rat brain homogenates. Lane 3 in $C$ contains purified recombinant PP2A catalytic subunits and in $D$ contains rabbit muscle lysates enriched in PP1 as standards $(S t d)$. Note that a fraction of the PP2A catalytic subunit associates with MTs, whereas PP1 catalytic subunits are recovered only in the soluble fraction. Molecular weight markers (in $\mathrm{kDa}$ ) are indicated on the right. The lanes in $A$ were loaded with $20 \mu \mathrm{g}$ of protein, and the lanes in $B$ and $D$ were loaded with $100 \mu \mathrm{g}$. Finally in $C$, lane $1=25 \mu \mathrm{g}$, lane $2=50 \mu \mathrm{g}$, lane $3=0.5 \mu \mathrm{g}$, and lane $4=20 \mu \mathrm{g}$. neurons, individual axonal MTs in NT2N neurons comprise predominantly Glu-MTs with a small amount of Tyr-MTs interdispersed along the entire lengths of these very long MTs. The discrepancy between the distribution of Glu- and Tyr-MTs in axonal MTs in sympathetic neurons versus NT2N neurons is unclear. It is possible that the distribution of axonal Glu-MTs and Tyr-MTs in the NT2N cells represents a more mature and stable MT in contrast to the sympathetic neuronal cultures used in previous studies (Baas and Black, 1990).

We have demonstrated here that treatment of NT2N cells with inhibitors of PP2A and PP1 results in the preferential destruction of axons, and we speculate that this is likely the consequence of multiple downstream signaling events regulated by PP2A and PP1. The present study also shows that the depolymerization of stable Glu-MTs, the hyperphosphorylation of tau, and the reduced binding of tau to MTs are among the critical events that are linked to the destruction of the axon. Other components of the neuronal cytoskeleton such as the neurofilament triplet proteins may also contribute to the degeneration of the axon induced by inhibitors of PP2A and PP1. Indeed, recent in vitro studies have shown that the inhibition of PP2A leads to the increased phosphorylation of neurofilament triplet proteins at specific sites, resulting in the disassembly of neurofilaments (Saito et al., 1995). Because one of the functions of neurofilaments is to stabilize the axon, the dissolution of the neurofilament network also could contribute to the destruction of the axon. Alternatively, the effects of PP2A and PP1 inhibitors on axons could be mediated by changes in the activities of a number of kinases such as MAP kinase and glycogen synthase kinase 3, because the activities of these kinases have been shown to be regulated by phosphatases (Gotoh et al., 1991; Cross et al., 1994). Thus, these and other phosphorylation-dependent enzymes may directly or indirectly regulate the stability of the neuronal cytoskeleton including MTs (Felix et al., 1990; Gotoh et al., 1991; Faruki et al., 1992). Although a number of other mechanisms could be implicated in the OK- and CL-A-induced destruction of axons in the NT2N cells, more detailed information on neuronal phosphatases is needed to test hypotheses about the nature of these mechanisms. For example, additional studies are needed to confirm whether PP2A is the only phosphatase that mediates the OK- and CL-Ainduced destabilization of MTs in the NT2N cells. Furthermore, the precise subunit composition of $\mathrm{PP} 2 \mathrm{~A}$ isoforms in neurons must be determined. Although we provide circumstantial evidence to implicate PP2A in the destabilization of MTs by OK and
CL-A in the NT2N cells, and this is consistent with the recent studies of PP2A in non-neuronal cells (Sontag et al., 1995, 1996), alternative experimental strategies and further research on neuronal MTs and phosphatases are needed to assess the validity of our interpretation of the data reported here.

These uncertainties notwithstanding, the results presented here suggest that the downregulation of phosphatases such as PP2A and PP1 may be sufficient to set off a cascade of events that leads to the genesis of neurofibrillary lesions. This cascade includes the selective depolymerization of the more stable GluMTs, as well as an increase in the phosphorylation of tau, and the inability of this hyperphosphorylated tau to bind and stabilize MTs, i.e., abnormalities that distinguish PHFtau from normal tau. We speculate that these events lead to the dissolution of the MT network, the dying back of the axon, and the degeneration of tangle-bearing neurons in AD (Bramblett et al., 1993; Lee and Trojanowski, 1995; Trojanowski et al., 1996; Goedert et al., 1997). Further studies of these events may provide insights into the role of neurofibrillary lesions in the degeneration of neurons in AD.

\section{REFERENCES}

Andrews PW, Damjanov I, Simon D, Banting GS, Carlin C, Dracopoli NS, Fogh J (1984) Pluripotent embryonal carcinoma clones derived from the human teratocarcinoma cell line NTera-2. Lab Invest $50: 147-162$.

Baas PW, Black MM (1990) Individual microtubules in the axon consist of domains that differ in both composition and stability. J Cell Biol 111:495-509.

Baas PW, Slaughter T, Brown A, Black MM (1991) Microtubule dynamics in axons and dendrites. J Neurosci Res 30:134-153.

Bernhardt R, Matus A (1984) Light and electron microscopic studies of the distribution of microtubule-associated protein 2 in rat brain: a difference between dendritic and axonal cytoskeletons. J Comp Neurol 226:203-221.

Bialojan C, Takai A (1988) Inhibitory effect of a murine-sponge toxin, okadaic acid, on protein phosphatases. Specificity and kinetics. Biochem J 256:283-290.

Blose SH, Meltzer DI, Feramisco JR (1984) 10nm filaments are induced to collapse in living cells microinjected with monoclonal and polyclonal antibodies against tubulin. J Cell Biol 98:847-858.

Bramblett GT, Trojanowski JQ, Lee VM-Y (1992) Regions with abundant neurofibrillary pathology in human brain exhibit a selective reduction in levels of binding-competent tau and accumulation of abnormal tau-isoforms (A68 proteins). Lab Invest 66:212-222.

Bramblett GT, Goedert M, Jakes R, Merrick SE, Trojanowski JQ, Lee VM-Y (1993) Abnormal tau phosphorylation at Ser396 in Alzheimer's disease recapitulates development and contributes to reduced microtubule binding. Neuron 10:1089-1099. 
Bulinski JC, Gundersen GG (1991) Stabilization and post-translational modification of microtubules during cellular morphogenesis. BioEssays 13:285-293.

Cohen P, Klumpp S, Schelling DL (1989) An improved procedure for identifying and quantitating protein phosphatases in mammalian tissues. FEBS Lett 250:596-600.

Cohen P, Holmes CFB, Tsukitani Y (1990) Okadaic acid: a new probe for the study of cellular regulation. Trends Biochem Sci 15:98-102.

Cross DAE, Alessi DR, Vandenheede JR, McDowell HE, Hundal HS, Cohen P (1994) The inhibition of glycogen synthase kinase-3 by insulin and insulin-like growth factor 1 in the rat skeletal muscle cell line L6 is blocked by wortmanin, but not by rapamycin: evidence that wortmanin blocks activation of the mitogen-activated protein kinase pathway in L6 between Ras and Raf. Biochem J 303:21-26.

Drewes G, Trinczek B, Illenberger S, Biernat J, Schmitt-Ulms G, Meyer HE, Mandelkow E-M, Mandelkow E (1995) Microtubule-associated protein/microtubule affinity-regulating kinase (p110mark). A novel kinase that regulates tau-microtubule interaction and dynamic instability by phosphorylation at the Alzheimer-specific site serine-262. J Biol Chem 270:7679-7688.

Drubin D, Kobayashi S, Kirschner M (1986) Association of tau protein with microtubules in living cells. Ann NY Acad Sci 466:257-268.

Faruki S, Doree M, Karsenti E (1992) Cdc2 kinase-induced destabilization of MAP2-coated microtubules in Xenopus egg extracts. J Cell Sci 101:69-78.

Felix MA, Cohen P, Karsenti E (1990) Cdc2 H1 kinase is negatively regulated by a type $2 \mathrm{~A}$ phosphatase in the Xenopus early embryonic cell cycle: evidence from the effects of okadaic acid. EMBO J 9:675-683.

Geisert EE, Johnson HG, Binder LI (1990) Expression of microtubuleassociated protein 2 by reactive astrocytes. Proc Natl Acad Sci USA 87:3967-3971.

Goedert M, Cohen ES, Jakes R, Cohen P (1992) p42 MAP kinase phosphorylation sites in microtubule-associated protein tau are dephosphorylated by protein phosphatase 2A1. Implications for Alzheimer's disease. FEBS Lett 312:95-99.

Goedert M, Jakes R, Crowther RA, Six J, Lubke U, Vandermeeren M, Cras P, Trojanowski JQ, Lee VM-Y (1993) The abnormal phosphorylation of tau protein at Ser-202 in Alzheimer disease recapitulates phosphorylation during development. Proc Natl Acad Sci USA 90:5066-5070.

Goedert M, Jakes R, Crowther RA, Cohen P, Vandermeeren M, Cras P (1994) Epitope mapping of monoclonal antibodies to the paired helical filaments of Alzheimer's disease: identification of phosphorylation sites in tau. Biochem J 301:871-877.

Goedert M, Trojanowski JQ, Lee VM-Y (1997) The neurofibrillary pathology of Alzheimer's disease. In: The molecular and genetic basis of neurological disease, Second Edition (Prusiner SB, Rosenberg RN, Di Mauro S, Barchi RL, eds), pp 613-628. Boston: Butterworth Heineman.

Goode BL, Feinstein SC (1994) Identification of a novel microtubule binding and assembly domain in the developmentally regulated interrepeat region of tau. J Cell Biol 124:769-782.

Goslin K, Banker G (1990) Rapid changes in the distribution of GAP-43 correlate with the expression of neuronal polarity during normal development and under experimental conditions. J Cell Biol 110:1319-1331.

Goslin K, Banker G (1991) Rat hippocampal neurons in low-density culture. In: Culturing nerve cells (Banker G, Goslin K, eds). Cambridge: MIT.

Gotoh Y, Nishida E, Matsuda S, Shiina N, Kosake H, Shiokawa K, Akiyama T, Ohta K, Sakai H (1991) In vitro effects on microtubule dynamics of purified Xenopus M phase-activated MAP kinase. Nature 349:251-254.

Greenberg SG, Davies P, Schein JD, Binder LI (1992) Hydrofluoric acid-treated tau PHF proteins display the same biochemical properties as normal tau. J Biol Chem 267:564-569.

Gundersen GG, Bulinski JC (1988) Selective stabilization of microtubules oriented toward the direction of cell migration. Proc Natl Acad Sci USA 85:5946-5950.

Gundersen GG, Kalnoski MH, Bulinski JC (1984) Distinct populations of microtubules: tyrosinated and nontyrosinated alpha tubulin are distributed differently in vivo. Cell 38:779-789.

Gurland G, Gundersen GG (1993) Protein phosphatase inhibitors in- duce the selective breakdown of stable microtubules in fibroblasts and epithelial cells. Proc Natl Acad Sci USA 90:8827-8831.

Hasegawa M, Morishima-Kawashima M, Takio K, Suzuki M, Titani K, Ihara Y (1992) Protein sequence and mass spectrometric analyses of tau in the Alzheimer's disease brain. J Biol Chem 267:17047-17054.

Ishihara H, Martin BL, Brautigan DL, Karaki H, Ozaki H, Kato Y, Fusentani N, Watabe S, Hashimoto K, Uemura D, Hartshorne D (1989) Calyculin A and okadaic acid: inhibitors of protein phosphatase activity. Biochem Biophys Res Commun 159:871-877.

Khawaja S, Gundersen GG, Bulinski JC (1988) Enhanced stability of microtubules enriched in detyrosinated tubulin is not a direct function of detyrosination level. J Cell Biol 106:141-149.

Kilmartin JV, Wright B, Milstein C (1982) Rat monoclonal anti-tubulin antibodies derived by using a new non-secreting rat cell line. J Cell Biol 93:576-582.

Kosik KS, Orecchio LD, Binder L, Trojanowski JQ, Lee VM-Y, Lee G (1988) Epitopes that span the tau molecule are shared with paired helical filaments. Neuron 1:817-825.

Kreis TE (1987) Microtubules containing detyrosinated tubulin are less dynamic. EMBO J 6:2597-2606.

Ksiezak-Reding H, Chien CH, Lee VM-Y, Yen SH (1990) Mapping of the Alz50 epitope in microtubule-associated proteins tau. J Neurosci Res 25:412-419.

Lee VM-Y, Andrews PW (1986) Differentiation of NTERA-2 clonal human embryonal carcinoma cells into neurons involves the induction of all three neurofilament proteins. J Neurosci 6:514-521.

Lee VM-Y, Trojanowski JQ (1995) Tau proteins and their significance in the pathobiology of Alzheimer's disease. In: Neuroscience perspectives: pathobiology of Alzheimer's disease (Goate AM, Ashall F, eds), pp 41-58. London: Academic.

Lee VM-Y, Balin BJ, Otvos LJ, Trojanowski JQ (1991) A68: a major subunit of paired helical filaments and derivatized forms of normal tau. Science 251:675-678.

Lindwall G, Cole RD (1984) Phosphorylation affects the ability of tau protein to promote microtubule assembly. J Biol Chem 259:5301-5305.

Matsuo ES, Shin R-W, Billingsley ML, Van de Voorde A, O'Connor M, Trojanowski JQ, Lee VM-Y (1994) Biopsy-derived adult human brain tau is phosphorylated at many of the same sites as Alzheimer's disease paired helical filament tau. Neuron 13:989-1002.

Mawal-Dewan M, Henley J, Van de Voorde A, Trojanowski JQ, Lee VM-Y (1994) The phosphorylation state of tau in the developing rat brain is regulated by phosphoprotein phosphatases. J Biol Chem 269:30981-30987.

Merrick SE, Demoise DC, Lee VM-Y (1996) Site-specific dephosphorylation of tau protein at $\mathrm{Ser}^{202} / \mathrm{Thr}^{205}$ in response to microtubule depolymerization in cultured human neurons involves protein phosphatase 2A. J Biol Chem 271:5589-5594.

Morishima-Kawashima M, Hasegawa M, Takio K, Suzuki M, Yoshida H, Titani K, Ihara Y (1995) Proline-directed and non-proline-directed phosphorylation of PHF-tau. J Biol Chem 270:823-829.

Otvos L, Feiner L, Lang E, Szendrei M, Lee VM-Y (1994) The monoclonal antibody PHF-1 recognizes tau protein phosphorylated at serine residues 396 and 404. J Neurosci Res 39:669-673.

Piperno G, Fuller MT (1985) Monoclonal antibodies specific for an acetylated form of alpha-tubulin recognize the antigen in cilia and flagella from a variety of organisms. J Cell Biol 101:2085-2094.

Piperno G, LeDizet M, Chang X-j (1987) Microtubules containing acetylated $\alpha$-tubulin in mammalian cells in culture. J Cell Biol 104:289-302.

Pleasure SJ, Lee VM-Y (1993) NTera 2 cells: a human cell line which displays characteristics expected of a human neuronal progenitor cell. J Neurosci Res 35:585-602.

Pleasure SJ, Lee VM-Y, Nelson DL (1990) Site-specific phosphorylation of the middle molecular weight human neurofilament protein in transfected non-neuronal cells. J Neurosci 10:2428-2437.

Pleasure SJ, Page C, Lee VM-Y (1992) Pure, postmitotic, polarized human neurons derived from NTera2 cells provide a system for expressing exogenous proteins in terminally differentiated neurons. J Neurosci 12:1802-1815.

Saito T, Shima H, Osawa Y, Nagao M, Hemmings HA, Kishimoto T, Hisanaga S (1995) Neurofilament-associated protein phosphatase 2A: its possible role in preserving neurofilaments in filamentous states. Biochemistry 34:7376-7384.

Saxton WM, Stample DL, Leslie RJ, Salmon ED, Zavortink M, McIntosh JR (1984) Tubulin dynamics in cultured mammalian cells. J Cell Biol 99:2175-2186. 
Schiff PB, Fant J, Horwitz SB (1979) Promotion of microtubule assembly in vitro by taxol. Nature 277:665-667.

Schulze E, Asai DJ, Bulinski JC, Kirschner M (1987) Posttranslational modification and microtubule stability. J Cell Biol 105:2167-2177.

Sontag E, Nunbhakdi-Craig V, Bloom GS, Mumby MC (1995) A novel pool of protein phosphatase $2 \mathrm{~A}$ is associated with microtubules and is regulated during the cell cycle. J Cell Biol 128:1131-1144.

Sontag E, Nunbhakdi-Craig V, Lee G, Bloom GS, Mumby MC (1996) Regulation of the phosphorylation state and microtubule-binding activity of tau by protein phosphatase 2A. Neuron 17:1201-1207.

Trojanowski JQ, Schuck T, Schmidt ML, Lee VM-Y (1989) Distribution of tau proteins in the normal human central and peripheral nervous system. J Histochem Cytochem 37:209-215.

Trojanowski JQ, Clark CM, Schmidt ML, Arai H, Zhu C, Mawal-Dewan
M, Lee VM-Y (1996) Implications of tau-rich neurofibrillary lesions for the pathobiology and diagnosis of Alzheimer's disease. In: Current neurology, Vol XVI (Appell SH, ed), pp 93-113.

Vallee RB (1982) A taxol-dependent procedure for the isolation of microtubules and microtubule-associated proteins (MAPs). J Cell Biol 92:435-442.

Webster DR, Gundersen GG, Bulinski JC, Borisy GG (1987a) Assembly and turnover of detyrosinated tubulin in vivo. J Cell Biol 105:265-276.

Webster DR, Gundersen GG, Bulinski JC, Borisy GG (1987b) Differential turnover of tyrosinated and detyrosinated microtubules. Proc Natl Acad Sci USA 84:9040-9044.

Weingarten MD, Lackwood AH, Hwo S-Y, Kirschner MW (1975) A protein factor essential for microtubule assembly. Proc Natl Acad Sci USA 72:1858-1863. 